\title{
Inorganic filler content of resin-based luting agents and the color of ceramic veneers
}

\section{Fabíola Jardim BARBON ${ }^{(a)}$ Rafael Ratto de MORAES(a) Joseane Viccari CALZA(b) Ana Paula PERRONI (a) Aloísio Oro SPAZZIN(b) Noéli BOSCATO(a)}

(a) Universidade Federal de Pelotas-UFPel, Graduate Program in Dentistry, Pelotas, RS, Brazil.

(b)Faculdade Meridional-IMED, Graduate Program in Dentistry, RS, Brazil.

Declaration of Interests: The authors certify that they have no commercial or associative interest that represents a conflict of interest in connection with the manuscript.

\section{Corresponding Author:}

Noéli Boscato

E-mail: noeliboscato@gmail.com

hitps://doi.org/10.1590/1807-3107bor-2018.vol32.0049

Submitted: January 12, 2018

Accepted for publication: April 10, 2018

Last revision: April 25, 2018

\begin{abstract}
The influence of inorganic filler content of resin-based luting agents (RBLAs) on color change $\left(\Delta \mathrm{E}_{00}\right), C I E L^{*} \mathrm{a}^{*} \mathrm{~b}^{*}$ (individual color coordinates), and translucency parameters (TP) of simulated ceramic laminate veneer (CLV) was investigated. RBLAs with low, intermediate, and high inorganic filler content $(55 \%, 65 \%$, and $75 \%$ mass fractions, respectively) were prepared. Feldspar ceramic (Vitablocs Mark II) specimens $(1.2 \mathrm{~mm} \times 0.8 \mathrm{~mm}, \mathrm{~A} 1 \mathrm{C}$ shade) were bonded to simulated composite resin substrates $(1.6 \mathrm{~mm} \times 1.2 \mathrm{~mm}, \mathrm{~A} 2 \mathrm{D}$ shade) using three experimental and a commercial (RelyX Veneer) RBLA (translucent shade). The $\Delta \mathrm{E}_{00}$ was calculated by CIEDE2000 color difference metric under three conditions (before, immediately after, and $24 \mathrm{~h}$ after luting). The TP was calculated using CIEL*a*b* color coordinates measured over white and black backgrounds. Surface morphology of the RBLAs was analyzed. One-way and two-way analyses of variance with a post-hoc Tukey's test were used respectively to calculate TP, CIEL*a*b* coordinates, and $\Delta \mathrm{E}_{00}(\mathrm{a}=0.05)$. Overall, the tested RBLAs presented clinically visible $\Delta \mathrm{E}_{00}$ values under the three conditions evaluated. For all RBLAs, higher $\Delta \mathrm{E}_{00}$ values were observed between measurements obtained before and immediately after luting. Different inorganic filler content did not significantly increase the opacity of the ceramic-luting agents-resin composite set. The variation in inorganic filler content did not influence significantly the TP of simulated CLV; although all of the experimental RBLAs tested yielded $\Delta \mathrm{E}_{00}$ above the perceptibility threshold. The $\mathrm{L}^{*}, \mathrm{a}^{*}$, and $b^{*}$ individual color coordinates were cementation-dependent.
\end{abstract}

Keywords: Ceramics; Dental Cements; Color.

\section{Introduction}

Restorative procedures involving ceramic laminate veneers (CLVs) offer minimum removal of dental structure and proper reestablishing of dental aesthetic and anatomic patterns. ${ }^{1,2}$ Several all-ceramic systems are currently available for fabrication of CLVs. Among these, feldspar ceramic is widely used because of its significant aesthetic and optical properties attributed to high content of vitreous phase in its composition. ${ }^{3}$ However, this material presents limited mechanical strength ${ }^{4}$ and its clinical success is based on proper quality of the interfacial bond between ceramic and dental substrate. The quality of this bonding depends on 
the adhesive procedures that are controlled in part by ceramic surface treatment and the materials used for adhesive cementation, ${ }^{5}$ including the resin-based luting agent (RBLA) ${ }^{5,6}$

The influence of the shade $e^{2,7,8}$ and color stability of light or dual-cured $9,10,11,12,13,14$ RBLA on the final color of thin ceramic restorations has been widely studied. ${ }^{15,16}$ Studies also have suggested that the inorganic filler content of RBLAs can influence their adequate penetration into the grooves produced by ceramic surface treatment, acting on quality and durability of the adhesive interface. ${ }^{6,17,18}$ Studies have investigated the influence of resin composite inorganic filler content on restoration brightness, ${ }^{19}$ elastic moduli on ceramic strengthening, ${ }^{19,20}$ shape of filler, and particle size on color change of resin composite restorations, ${ }^{21,22,23,24,25,26}$ however, there is a lack of studies on the role of inorganic filler content of the luting agent on the final color of CLV.

Since the color of thin CLV can be affected by several factors and achieving natural tooth-like restoration is still one of the greatest challenges for restorative dentistry, $8,10,27,28,29,30$ this study evaluated the influence of low, intermediate, and high barium borosilicate inorganic filler content $(55 \%, 65 \%$, and $75 \%$ of mass fraction, respectively) of experimental resin luting agent on the translucency parameter (TP), color change $\left(\Delta \mathrm{E}_{00}\right)$, and CIEL*a*b* individual color coordinates of simulated CLVs. The hypotheses tested were that the higher inorganic filler content had a larger effect on the optical properties $\left(\Delta \mathrm{E}_{00}\right.$ and TP) of simulated CLV.

\section{Methodology}

\section{Study design}

This in vitro study evaluated the influence of inorganic filler content of experimental RBLAs on the color of CLVs. RBLAs with low (55 wt\%), intermediate $(65 \mathrm{wt} \%)$, or high $(75 \mathrm{wt} \%)$ filler loading were evaluated. The commercial resin luting agent RelyX Veneer (3M ESPE; St Paul, MN, USA) was tested as a reference, with $66 \mathrm{wt} \%$ fraction of inorganic filler content. All luting agents were translucent in shade. The response variables tested were $\Delta \mathrm{E}_{00}$ and TP $(\mathrm{n}=10)$ based on CIEL*a* $\mathrm{b}^{*}$ color coordinates measured with a spectrophotometer (Easyshade Advanced 4.0; Vita Zahnfabrik, Bad Säckingen, Germany).

The feldspar ceramic CAD/CAM blocks (I14 A1 Vitablocs Mark II for Cerec; Vita Zahnfabrik, Bad Säckingen, Germany) were evaluated over a simulated dental substrate (A2D shade) and the $\Delta \mathrm{E}_{00}$ was calculated by CIEDE2000 color difference metric $^{21}$ under three conditions: (i) $(\mathrm{B} \times \mathrm{IL})$, before (without luting agent) versus immediately after luting; (ii) $(\mathrm{B} \times \mathrm{IW})$ before versus $24 \mathrm{~h}$ after luting and water immersion; and (iii) (IL $\times$ WI) immediately after luting versus $24 \mathrm{~h}$ in water immersion. The TP was calculated using CIEL*a*b* color coordinates measured over black and white backgrounds.

\section{Formulation of experimental resin-based luting agents}

The experimental RBLAs were formulated by combining $50 \%$ of mass fraction of urethane dimethacrylate (UDMA) and triethylene glycol dimethacrylate (TEGDMA) (Esstech Inc.; Essington, PA, USA). For the luting agents, $0.4 \%$ mass fraction of camphorquinone (Sigma-Aldrich; St. Louis, MO, USA) was used as photosensitizer, and $0.8 \%$ mass fraction of ethyl 4-dimethylaminobenzoate (Sigma-Aldrich) was used as coinitiator (Table 1). The monomers and mass fractions of the luting agents were defined in pilot studies. Therefore, three different RBLAs were prepared using different inorganic filler contents: $55 \mathrm{wt} \%$ (low), $65 \mathrm{wt} \%$ (intermediate), and $75 \mathrm{wt} \%$ (high). Barium borosilicate glass particles (2 $\mu \mathrm{m}$ average size) coated with $1 \%$ mass fraction of silane coupling agent (V-119-4120; Essington, PA, USA) were used as inorganic filler content. The materials were mechanically mixed using a centrifugal mixer (SpeedMixer DAC150; FlackTek, Landrum, SC, USA) at $1500 \mathrm{rpm}$ during $20 \mathrm{~s}$ to produce homogeneous materials. ${ }^{19}$

A light-cured RBLA (RelyX Veneer; 3M ESPE), widely employed for the adhesive cementation of CLV, was used as commercial reference. This luting agent presents $66 \mathrm{wt} \%$ fraction of inorganic filler content according to the manufacturer, ${ }^{31}$ which is similar to the intermediate experimental luting agent tested. 
Table 1. Resin-based luting agent compositions.

\begin{tabular}{|c|c|c|c|c|c|c|}
\hline Luting agents & Manufacturer & Shade & $\begin{array}{l}\text { Monomer } \\
\text { composition }\end{array}$ & Filler composition & Filler (weight/ \%) & $\begin{array}{c}\text { Polymerization } \\
\text { (cure /composition) }\end{array}$ \\
\hline Commercial & RelyX Veneer (3M ESPE) & Translucent & $\begin{array}{l}\text { BisGMA/ } \\
\text { TEGDMA }\end{array}$ & Zi-Si $(0.6 \mu \mathrm{m})$ & $66 \%$ & $\begin{array}{l}\text { Light / not informed by } \\
\text { the manufacturer }\end{array}$ \\
\hline Low & Experimental & Translucent & $\begin{array}{l}\text { UDMA / } \\
\text { TEGDMA }\end{array}$ & Ba-Bo-Si $(2 \mu \mathrm{m})$ & $55 \%$ & $\begin{array}{l}\text { Light / camphorquinone } \\
\text { /EDAB }\end{array}$ \\
\hline Intermediate & Experimental & Translucent & $\begin{array}{l}\text { UDMA / } \\
\text { TEGDMA }\end{array}$ & Ba-Bo-Si $(2 \mu \mathrm{m})$ & $65 \%$ & $\begin{array}{l}\text { Light / camphorquinone } \\
\text { /EDAB }\end{array}$ \\
\hline High & Experimental & Translucent & $\begin{array}{l}\text { UDMA / } \\
\text { TEGDMA }\end{array}$ & Ba-Bo-Si $(2 \mu \mathrm{m})$ & $75 \%$ & $\begin{array}{l}\text { Light / camphorquinone } \\
\text { /EDAB }\end{array}$ \\
\hline
\end{tabular}

\section{Preparation of the feldspar ceramic specimens}

Feldspar ceramic CAD/CAM blocks were milled under water cooling originating a cylindrical shape (12 $\mathrm{mm}$ in diameter $\times 18 \mathrm{~mm}$ in thickness). The cylinders were cut into $0.8-\mathrm{mm}$ thickness discs $(\mathrm{n}=10$ / group) ${ }^{19}$ using a diamond saw (Diamond Blade $5^{\prime \prime} \mathrm{x}$ $0.015^{\prime \prime}$ x 0.5", Lapmaster Wolters International, Mt. Prospect, USA) under water cooling (Isomet1000; Buehler, Lake Bluff, IL, USA), simulating monolayer restorations. ${ }^{19,32}$ All discs had both sides sequentially manually wet-polished using 600 and 1200-grit $\mathrm{SiC}$ papers (Norton SA, Guarulhos, SP, Brazil). The final dimensions of each specimen were measured using a digital caliper with 0.001-mm accuracy (Mitutoyo, Tokyo, Japan).

\section{Preparation of simulated dental substrate}

Cylinders $(12 \mathrm{~mm}$ in diameter $\times 18 \mathrm{~mm}$ in thickness) from dentin resin composite shade A2 (Llis, FGM, Joinville, SC, Brazil) were fabricated incrementally using polydimethylsiloxane molds (Clonage; New DFL, Rio de Janeiro, RJ, Brazil). Each increment was light-cured using a LED unit (Radii; SDI Limited, Bayswater, Victoria, Australia) at $1200 \mathrm{~mW} / \mathrm{cm}^{2}$ irradiance following the manufacturer's recommendations. The cylinders were cut into $1.6-\mathrm{mm}$ thickness discs using a diamond saw (Diamond Blade 5"x 0.015" x 0.5", Lapmaster Wolters International) under water cooling (Isomet1000; Buehler) originating a total of 40 resin discs $(n=10 / \text { group })^{8}$ prepared to evaluate $\Delta \mathrm{E}_{00}$ and TP. The top surface of specimens was manually polished with 600 and 1200-grit SiC abrasive papers under running water.

\section{Luting procedures for cementation of ceramic discs to simulated dental substrate}

The polished ceramic disc surfaces were etched with $10 \%$ hydrofluoric acid for $60 \mathrm{~s}$ (Condac Porcelain $10 \%$; FGM), washed for $60 \mathrm{~s}$, and dried with water and oil-free compressed air for $30 \mathrm{s.}{ }^{32}$ For cleaning, the ceramic and resin composite discs were etched with 37\% phosphoric acid (Condac 37; FGM) for $30 \mathrm{~s}$ and washed and dried as previously described. Two layers of silane coupling agent (RelyX Ceramic Primer; 3M ESPE) were applied to ceramic discs using a microbrush (Cavibrush regular, FGM), and after $60 \mathrm{~s}$, they were dried with compressed air for $30 \mathrm{~s}$ and a thin layer of adhesive Single Bond 2 (3M ESPE) was applied. ${ }^{10,19}$

For each group, a standard volume of the RBLA, sufficient to cover the surface of the ceramic discs, was applied to the center, and two matrix strips were lightly pressed to extrude the luting agent and create a film thickness between 100 to $250 \mu \mathrm{m} .{ }^{33,34,35}$ The ceramic discs were luted to resin composite discs with the different RBLAs tested. The resin composite disc was centrally orientated on a leveled loading platform and its top ceramic surface was loaded with $750 \mathrm{gF}$ for 2 min. ${ }^{10}$ Luting agent excess was removed using a microbrush (Cavibrush regular, FGM) and light-cured for $40 \mathrm{~s}$ at all interfaces, and four groups were originated according to the RBLA used. The specimens were dry-stored at $37^{\circ} \mathrm{C}$ for 24 $\mathrm{h}$ in lightproof containers. ${ }^{19}$

Due to its high viscosity, the experimental luting agent loaded with high inorganic filler content was heated to increase its wettability on the ceramic surface prior to cementation. The luting agent was heated up to the maximum temperature of $60^{\circ} \mathrm{C}$ for $30 \mathrm{~min}^{10,36,37}$ to avoid monomer conversion. 


\section{Evaluation of $\Delta \mathrm{E}_{00}$ and $\mathrm{CIEL} \mathrm{L}^{*} \mathrm{a}^{*} \mathrm{~b}^{*}$ color coordinates}

The $\Delta \mathrm{E}_{00}$ was estimated by calculating the CIEDE2000 color variation between the feldspar ceramic bonded to simulated dental substrate discs $(n=40)$ using the experimental and commercial RBLAs tested, under three conditions: B $\times$ IL, B $\times$ IW, and IL $\times$ WII according to the following equation: ${ }^{28}$

$$
\Delta \mathrm{E}_{00}=\left[\left(\Delta \mathrm{L}^{\prime} / \mathrm{K}_{\mathrm{L}} \mathrm{S}_{\mathrm{L}}\right)^{2}+\left(\Delta \mathrm{C}^{\prime} / \mathrm{K}_{\mathrm{C}} \mathrm{S}_{\mathrm{C}}\right)^{2}+\left(\Delta \mathrm{H}^{\prime} / \mathrm{K}_{\mathrm{H}} \mathrm{S}_{\mathrm{H}}\right)^{2}+\right.
$$
$\left.\mathrm{R}_{\mathrm{T}}\left(\Delta \mathrm{C}^{\prime} / \mathrm{K}_{\mathrm{C}} \mathrm{S}_{\mathrm{C}}\right)\left(\Delta \mathrm{H}^{\prime} / \mathrm{K}_{\mathrm{H}} \mathrm{S}_{\mathrm{H}}\right)\right]^{1 / 2}$

where $\Delta L^{\prime}, \Delta C^{\prime}$, and $\Delta H^{\prime}$ are the differences in lightness, chroma, and hue between two sets of color coordinates. $R_{\mathrm{T}}$ is the rotation function that accounts for the interaction between chroma and hue differences in the blue region. $S_{\mathrm{L}}, S_{\mathrm{C}}$ and $S_{\mathrm{H}}$ are the weighting functions used to adjust the total color difference for variation in perceived magnitude with variation at the location of the color coordinate difference between two color readings. $K_{\mathrm{L}}, K_{\mathrm{C}}$, and $K_{\mathrm{H}}$ are the correction terms for the experimental conditions. The perceptibility and acceptability thresholds were set at $\Delta \mathrm{E}_{00}=0.8$ and $\Delta \mathrm{E}_{00}=1.8$, respectively ${ }^{38}$ All measurements were made using glycerin as liquid coupling medium between the background and the specimens. ${ }^{38}$

\section{Evaluation of TP}

The TP of the ceramic-luting agent-resin composite set was estimated by the difference between CIEL*a* ${ }^{*}$ color coordinates measured over a white background $\left(L^{*}=90.9, a^{*}=0.3, b^{*}=4.9\right)$ and a black background $\left(L^{*}=0.5, a^{*}=14.6, b^{*}=-21.5\right)$ using the following equation: ${ }^{28}$

$$
\mathrm{TP}=\left[\left(\mathrm{L}^{*}{ }^{-}-\mathrm{L}_{\mathrm{B}}^{*}\right)^{2}+\left(\mathrm{a}^{*}{ }_{\mathrm{W}}-\mathrm{a}^{*}{ }_{\mathrm{B}}\right)^{2}+\left(\mathrm{b}^{*}{ }_{\mathrm{W}}-\mathrm{b}^{*}{ }_{\mathrm{B}}\right)^{2}\right]^{1 / 2}
$$

where subscript $\mathrm{W}$ and subscript $\mathrm{B}$ refer to the color coordinates measured on the white and black backgrounds. All measurements were also made using glycerin as liquid coupling medium. ${ }^{39}$

\section{Scanning electron microscopy (SEM)}

One disc for each group $(6 \mathrm{~mm} \times 2 \mathrm{~mm})$ was prepared to evaluate the surface morphology of all luting agents. ${ }^{40}$ The specimens were embedded in epoxy resin (Redelease, São Paulo, SP, Brazil), ultrasonically cleaned with distilled water for $30 \mathrm{~min}$, dried at $37^{\circ} \mathrm{C}$, and polished using $600,1200,2000$, and 2500-grit $\mathrm{SiC}$ abrasive papers, followed by diamond suspensions (Polycrystalline Diamond Suspension, Buehler, Uzwil, Switzerland) of 3 and $1 \mu \mathrm{m}$. After that they were cleaned, dried, sputter-coated with gold-palladium, and examined using SEM (SSX-550, Shimadzu, Tokyo, Japan). The images were obtained at $\times 500$ and $\times 3000$ magnifications.

\section{Statistical analysis}

The Shapiro-Wilk test was used to assess the normality of data. One-way and two-way analyses of variances with a post-hoc Tukey's test were used respectively to calculate $\mathrm{TP}$ and $\Delta \mathrm{E}_{00}$ (conditions and groups). CIEL*a*b* individual color coordinate values were analyzed between groups using one-way analyses of variance with a post-hoc Tukey's test $(\alpha=0.05)$. Confidence intervals for the means $(95 \% \mathrm{CI})$ were also calculated.

\section{Results}

\section{$\Delta E_{00}$}

Table 2 shows the results of $\Delta \mathrm{E}_{00}$ for comparisons between groups and conditions. All experimental RBLAs yielded $\Delta \mathrm{E}_{00}$ values above 0.8 under the three conditions, which is the perceptibility threshold color difference for the CIEDE2000 method. ${ }^{38}$ For all RBLAs, significantly higher and lower $\Delta \mathrm{E}_{00}$ values were observed under the $\mathrm{B} \times \mathrm{IL}$ and IL $\times$ WI conditions, respectively $(p<0.001)$. Statistically significant differences were found for group comparisons $(p=0.039)$ under the three conditions; RelyX Veneer showed significantly lower $\Delta \mathrm{E}_{00}$ values under the IL $\times$ WI condition; while under the $\mathrm{B} \times \mathrm{IL}$ and $\mathrm{B} \times \mathrm{IW}$ conditions, the High group yielded significantly higher $\Delta \mathrm{E}_{00}$ values.

\section{CIEL* $\mathbf{a}^{*} \mathbf{b}^{*}$ color coordinates}

Table 3 shows the results for the CIEL*a* $b^{*}$ color coordinates $\left(L^{*}, a^{*}\right.$, and $\left.b^{*}\right)$ measured three times for all groups. There was no statistically significant 
Table 2. Means (standard deviations) for color change $\left(\Delta \mathrm{E}_{00}\right)$ for the comparisons of luting agents under different conditions

\begin{tabular}{lccc}
\hline Luting agent & $\mathrm{B} \times \mathrm{IL}$ & $\mathrm{B} \times \mathrm{IW}$ & $\mathrm{IL} \times \mathrm{WI}$ \\
\hline RelyX Veneer & $3.33(1.52) \mathrm{B}, \mathrm{a}$ & $2.74(1.20) \mathrm{B}, \mathrm{b}$ & $0.85(0.27) \mathrm{B}, \mathrm{c}$ \\
Low & $3.40(0.71) \mathrm{B}, \mathrm{a}$ & $2.60(1.14) \mathrm{B}, \mathrm{b}$ & $1.42(0.34) \mathrm{A}, \mathrm{c}$ \\
Intermediate & $3.50(1.27) \mathrm{B}, \mathrm{a}$ & $2.59(0.94) \mathrm{B}, \mathrm{b}$ & $1.47(0.76) \mathrm{A}, \mathrm{c}$ \\
High & $4.19(0.69) \mathrm{A}, \mathrm{a}$ & $3.50(0.99) \mathrm{A}, \mathrm{b}$ & $1.25(0.17) \mathrm{AB}, \mathrm{c}$ \\
\hline
\end{tabular}

Different uppercase letters in the same column and lowercase letters in the same row show significant differences between luting agents and conditions ( $p<0.05)$. Luting agents: RelyX Veneer, commercial; Low, $55 \%$ mass fraction; Intermediate, $65 \%$ mass fraction; High, $75 \%$ mass fraction groups. Conditions: Before luting vs immediately after luting $(B \times \mathrm{IL})$; before versus $24 \mathrm{~h}$ after luting and water immersion $(B \times I W)$; and immediately after luting versus $24 \mathrm{~h}$ in water immersion (IL $\times \mathrm{WI})$.

Table 3. Means (standard deviations) and $95 \%$ confidence intervals $(\mathrm{Cl})$ for individual $\mathrm{ClE} \mathrm{L}^{*}$, $\mathrm{a}^{*}$, and $\mathrm{b}^{*}$ color coordinates.

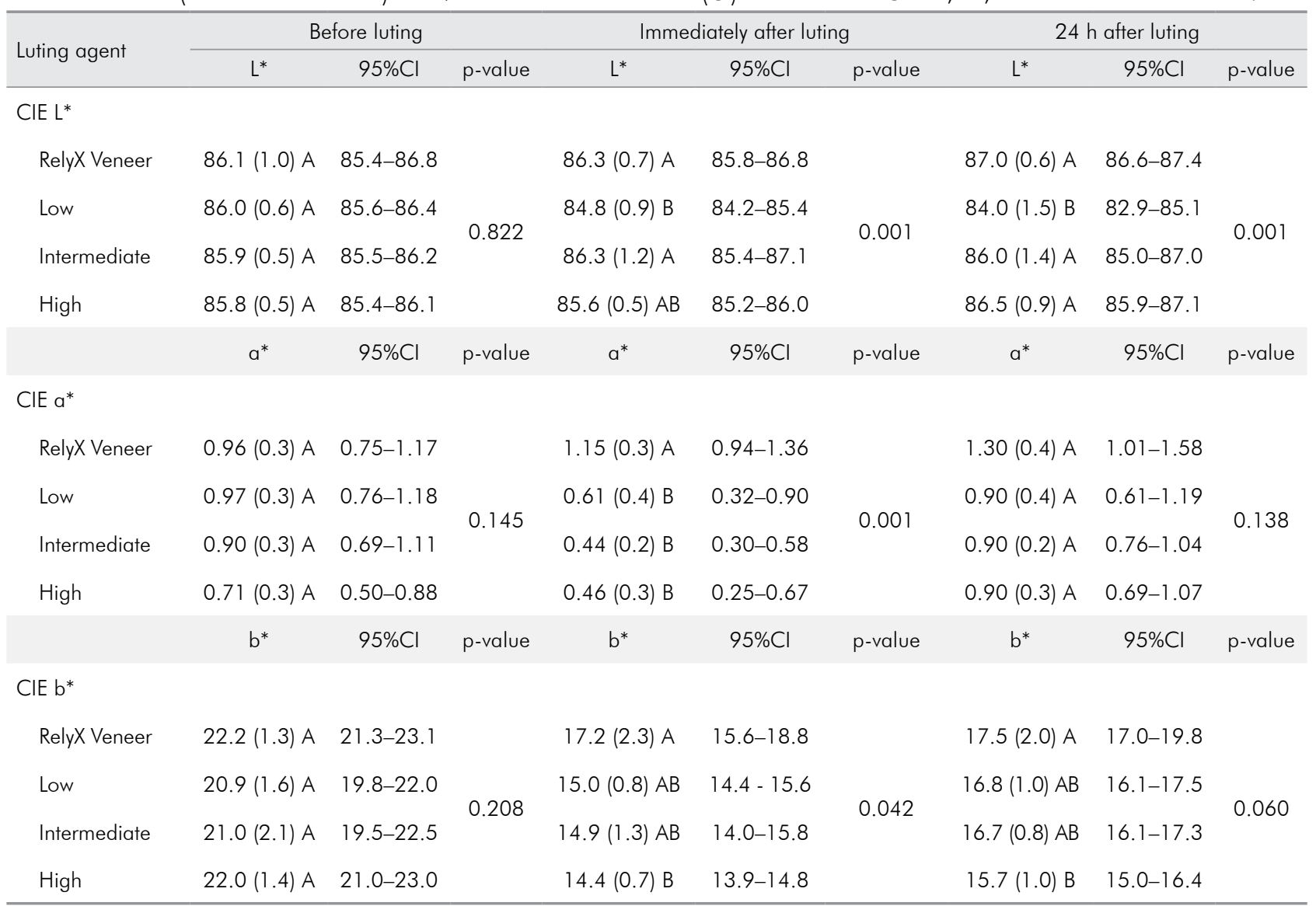

Different uppercase letters in the same column show significant differences between luting agents in each individual color coordinate $(p<0.05)$.

difference between the groups in any coordinates in the measurements before and $24 \mathrm{~h}$ after luting. A significant difference was observed in coordinates $L^{*}(p=0.001), a^{*}(p=0.001)$, and $b^{*}(p=0.042)$.

Significant differences in $\mathrm{L}^{*}$ values were observed between groups immediately after and $24 \mathrm{~h}$ after luting ( $p<0.001)$. The lowest $L^{*}$ values were found for the Low group $24 \mathrm{~h}$ after luting (84.0); and the highest $\mathrm{L}^{*}$ values were found $24 \mathrm{~h}$ after luting for the commercial reference group (87.0).

Regarding a* and $b^{*}$ coordinates, statistically significant differences were observed, respectively 
$(\mathrm{p}<0.001)$ and $(\mathrm{p}=0.042)$, immediately after luting with the highest $a^{*}(1.15)$ and $b^{*}(17.2)$ values found for the commercial reference group. Only positive $a^{*}$ and $b^{*}$ values were found.

\section{TP}

Figure 1 shows that there is no difference between the experimental luting agents, but there is a difference

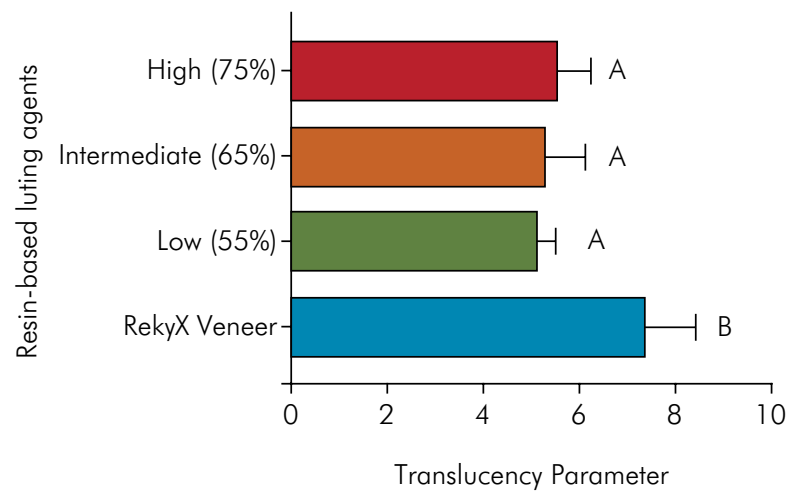

Figure 1. Translucency parameter (means + standard deviation) for resin-based luting agents. Different letters indicate statistically significant differences $(p<0.05)$. between them and the luting agent RelyX Veneer, which presented a higher TP.

\section{SEM}

Representative SEM images of RBLA surfaces are shown in Figure 2. The experimental luting agents revealed similar filler distribution according to the available resin matrix, in addition to larger and irregular filler particles. The commercial luting agent presented smaller and spherical filler particles, whereas the experimental RBLAs had irregularly shaped fillers.

\section{Discussion}

All experimental luting agents were prepared with TEGDMA and UDMA resinous monomeric matrix since previous studies reported higher color stability and translucency than that observed for Bis-GMA. ${ }^{2,25}$ Materials with translucent shade were prepared and/or selected because of their highest translucency values and refractive index than those of opaque and colored shades, ${ }^{25}$ thus,
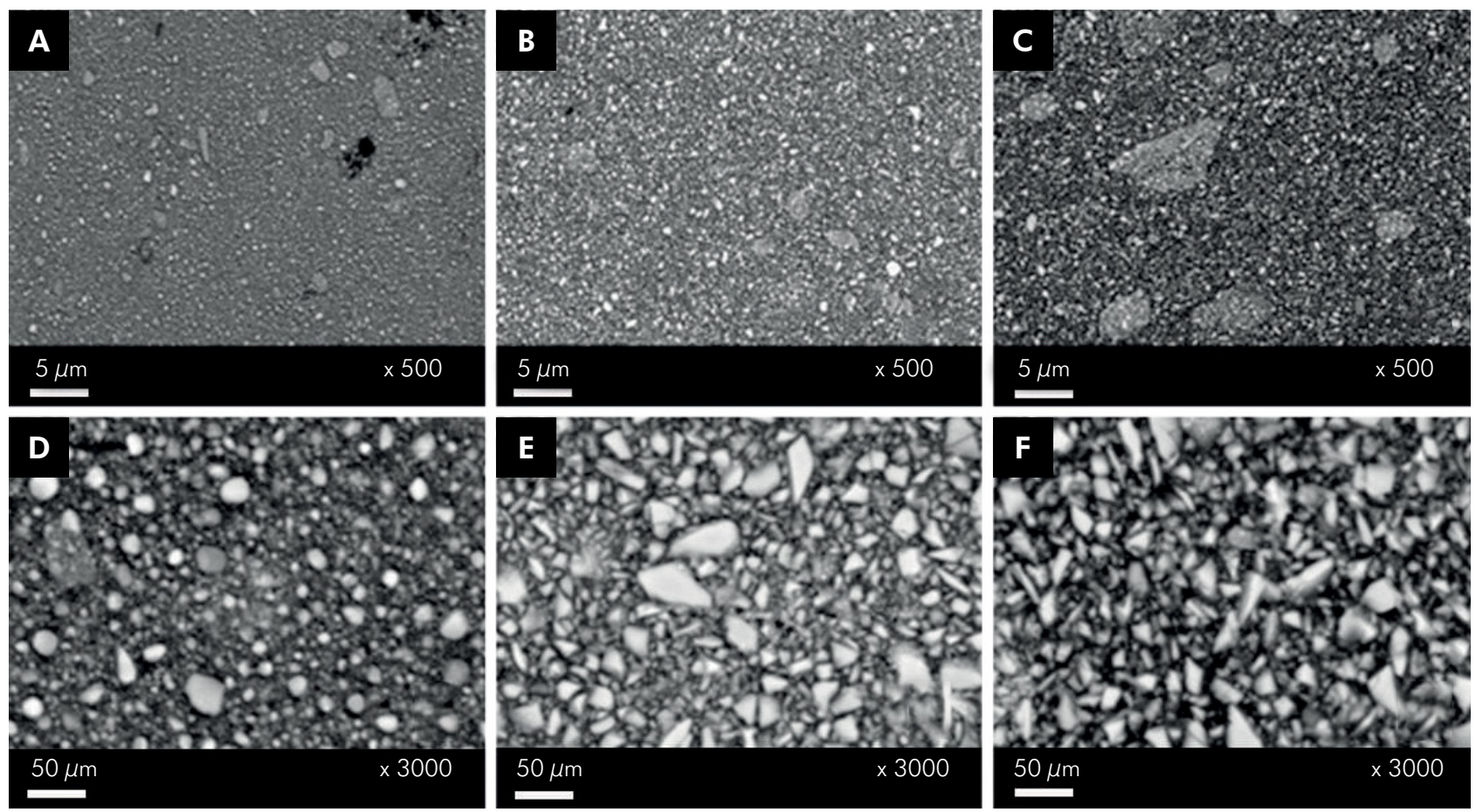

Figure 2. SEM images showing the distribution of inorganic fillers in the organic matrix of resin-based luting agents observed at $\times 500(A$ to $D)$ and $\times 3000(E$ to $H)$. The images in $A$ and $E$ show the commercial luting agent with smaller and spherical filler particles; the images in B and F (Low), C and G (Intermediate), and D and H (High) show the experimental resin-based luting agents. 
the influence of inorganic filler content would be better evaluated. Finally, color measurements were made with a spectrophotometer for accuracy and reproducibility. ${ }^{39}$

In this study, all of the tested luting agents yielded $\Delta \mathrm{E}_{00}$ values greater than 0.8 under the $\mathrm{B} \times$ IL and $B \times W I$ conditions, which is the perceptibility threshold for color differences according to a previous publication, ${ }^{38}$ confirming the first hypothesis of the study. These results are in agreement with those of previous studies on the influence of the commercial ${ }^{11,13,14,15,16}$ and experimental luting agents ${ }^{16}$ on the optical properties of translucent ceramic restorations. Overall, amongst the tested groups, the High group showed a more pronounced effect on the final color of the specimens under the $\mathrm{B} \times \mathrm{IL}$ and $\mathrm{B} \times \mathrm{IW}$ conditions. These results indicate that the mass fraction of the tested filler content influenced the $\Delta \mathrm{E}_{00}$ of the experimental luting agents. This result is in line with a previous study reporting that the inorganic content of resin composite should be selected for the best color reproduction of natural tooth color. ${ }^{22}$ Nevertheless, the Low and Intermediate groups yielded similar $\Delta \mathrm{E}_{00}$ values under the three conditions; whereas the best shade matching (i.e., lower $\Delta \mathrm{E}_{00}$ values) was obtained for specimens luted with the commercial luting agent $\left(\Delta \mathrm{E}_{00}=0.85 \pm 0.27\right)$ under the IL $\times$ WI condition. Probably the lower $\Delta \mathrm{E}_{00}$ values obtained for RelyX Veneer are due to the different refractive indices of commercial and experimental luting agents tested in this study. ${ }^{21,23}$ Therefore, it seems that differences in $\Delta \mathrm{E}_{00}$ values among materials could be overcome by organic matrix and filler properties such as particle size and shape, in addition to filler content, since light scattering and absorption by the matrix influence the optical properties. ${ }^{21,30}$ In fact, the size and distribution of filler particles into resin matrix seem to correlate directly with the results of this study; the experimental luting agents that presented larger filler particle dimension (average size of approximately $2 \mu \mathrm{m}$ ) and irregular shape showed higher $\Delta \mathrm{E}_{00}$ values compared to the commercial reference, in which the filler particle dimensions were smaller (average size of approximately $0.6 \mu \mathrm{m}$ ) and spherical. Thus, it seems that the size, shape, and volume fraction of fillers should be controlled for the best color reproduction, considering the refractive indices of filler and resin matrix. ${ }^{21,23}$

Based on the evaluated conditions, the highest $\Delta \mathrm{E}_{00}$ values were observed under $\mathrm{B} \times \mathrm{IL}$ and $\mathrm{B} \times \mathrm{IW}$ for all groups. This probably occurred because under these conditions the specimens were evaluated before and after luting. These results are in agreement with those of previous studies reporting that the luting agent plays an important role in the final color of thin CLVs. ${ }^{8,11,15}$ Under the $\mathrm{B} \times \mathrm{IW}$ condition, the specimens were immersed in water for $24 \mathrm{~h}$ and the lowest $\Delta \mathrm{E}_{00}$ values were observed, when compared with those obtained under the $\mathrm{B} \times \mathrm{IL}$ condition, in which the specimens were not stored in water. An explanation for changes in $\Delta \mathrm{E}_{00}$ values as a result of water exposure might be found in the composition of materials. It is known from the literature that resin-based composition allows water to penetrate the matrix or filler-matrix interface, producing color changes. ${ }^{26,30}$ This shows the influence of hydrating the restoration, even during a relatively short period $(24 \mathrm{~h})$. This is similar to what occurs in the oral cavity with oral fluid hydration. ${ }^{29}$ Despite the limitations of this study, this finding suggests that clinicians do not need a long hydration time for better color matching of CLV with the adjacent teeth. Nevertheless, statistically significant differences with lower $\Delta \mathrm{E}_{00}$ values were observed for RelyX Veneer under the IL $\times$ WI condition, where only the hydration of the ceramic-luting agent-resin composite set was evaluated immediately after luting versus $24 \mathrm{~h}$ in water immersion. From this finding, the amount of inorganic filler content $(75 \%, 65 \%, 55 \%$ experimental luting agent; $66 \%$ commercial luting agent) by itself could not be directly associated with the degree of color change found after storage. This is in accordance with Vichi et al., ${ }^{30}$ who stated that color changes could also be related to the mass fraction of the resin matrix (UDMA and TEGDMA for experimental luting agent; BisGMA and TEGDMA for commercial luting agent) and to filler properties. ${ }^{22}$

Regarding CIEL*a* ${ }^{*}$ individual color coordinates, low $L^{*}$ values were observed for the Low group immediately after and $24 \mathrm{~h}$ after luting. Our findings are in line with those of a previous study that evaluated resin composites with different particle sizes. This study 
reported decreased L* values for low particle sizes, ${ }^{21}$ while a* coordinate showed positive values, indicating a tendency toward a reddish color. The Low group presented lower $\mathrm{a}^{*}$ values after luting and the commercial reference increased $a^{*}$ values, indicating a greater tendency toward reddish tones than in the experimental groups. However, the low values found for this coordinate are clinically irrelevant.

For coordinates $\mathrm{a}^{*}$ and $\mathrm{b}^{*}$, the data have some similarities and counterpoints to another study, which showed a tendency towards reddish ( $a^{*}$ positive) and bluish ( $b^{*}$ negative) tones after immersion in water. ${ }^{21}$ Our findings demonstrate positive values in both coordinates, yielding yellowish $\left(b^{*}\right)$ and reddish $\left(a^{*}\right)$ tones. It is important to note that the time points observed in these studies were not similar, which could originate different results.

This study hypothesized that the TP would be affected depending on the inorganic filler content since it could produce higher opacity. Nonetheless, the amount of inorganic filler content did not yield statistically significant differences among the tested experimental luting agents; while the commercial reference showed significantly the highest TP values, thus rejecting this hypothesis (Figure1). An explanation for TP values found among the experimental luting agents could be that even the luting agent loaded with high inorganic filler content was properly homogenized using the mechanical mixing device (Figure 2). However, RelyX Veneer presented better homogeneous organic and inorganic matrices compared to the experimental groups. It is known from the literature that the homogeneous matrix phase provided lower color changes ${ }^{21,26}$ because of lower light reflection and dispersion coefficients, which could change the refractive index. ${ }^{18,21,22}$ The higher the refractive index difference between inorganic fillers and the matrix phase of resin composites, the greater the opacity of the materials, thanks to multiple reflection and refraction at the matrix filler interfaces..$^{22}$ In fact, color perception is directly related to scattering since the interface can modify the way in which the light is scattered by the particles. The interface between resin and fillers is one of the weakest points of the composite material, and materials with a higher mass fraction of organic filler may have modifications in the way the light is punctured by the particles, ${ }^{20,30}$ which may lead to TP changes in RBLAs. This may explain the highest TP values found for the High group among the experimental (Low and Intermediate) groups, and the highest TP values found for RelyX Veneer among all tested groups, according to surface morphology (Figure 2). The barium borosilicate filler was chosen in this study because it is widely used in dental resin composite formulations. These inorganic filler particles present an irregular shape, which may help explain the findings since irregular particles may change the propagation of light, thereby increasing the opacity of the material. ${ }^{37}$

The difficulty in comparing the products lies in the fact that manufacturers disclose few details about the proportion of monomers and filler particles and do not describe the type and concentration of silane, pigments, and opacifiers. Knowledge about material composition is important since not only the inorganic filler content but also filler shape and particle size could influence light transmittance characteristics. ${ }^{23}$ Our results indicate that filler content per se did not significantly affect the TP of the tested experimental luting agents. Thus, the optical performance of a commercial luting agent is unlikely to be predicted based solely on the available compositional data. ${ }^{18}$ According to the manufacturer, the commercial luting agent used in this study is composed of BisGMA and TEGDMA monomers, zirconia, and silica filler particles (average size of approximately $0.6 \mu \mathrm{m}$ ), and a patented dimethacrylate polymer that modifies the rheology of the material and provides a unique handling characteristic, allowing the luting agent to flow easily under pressure, providing uniform film, regardless of the inorganic filler content. ${ }^{31}$ In fact, the commercial reference composition differs from the tested experimental luting agents in some filler properties, including the average particle size of approximately $0.6 \mu \mathrm{m}$ and $2 \mu \mathrm{m}$ and the spherical and irregular shape of commercial and experimental luting agents, respectively (Figure 2). This finding corroborates that of a previous study that reported that materials containing smaller and irregularly shaped fillers showed higher light transmittance and diffusion angle distribution with a sharper peak, as compared to those containing larger and 
spherical fillers. ${ }^{23,30}$ Therefore, the highest TP values found for the commercial reference as compared to experimental luting agents with a similar amount of filler (Intermediate group) could be linked to the scattering coefficient of the particle diameter and to the wavelength of the incident visible light. ${ }^{22}$

One of the strengths of this study was the accuracy and reliability of shade records. Only one calibrated examiner performed all the readings, avoiding interexaminer variability. However, our study is not free of limitations, since this is an in vitro study with a short-term aging period, and the long-term aging effect on color stability of CLV luted with RBLAs is a complex phenomenon. Actually, these findings should be interpreted with caution, given that there are few studies on the influence of inorganic filler content on the optical properties of thinner CLV; nonetheless, this confirms that our data could help achieve a successful aesthetic treatment. It is important to point out that greater color variation is desirable in the clinical setting when a shade match between darker and lighter

\section{References}

1. Daou EE. Esthetic prosthetic restorations: reliability and effects on antagonist dentition. Open Dent J. 2015 Dec;9(1):473-81. https://doi.org/10.2174/1874210601509010473

2. Turgut S, Bagis B. Colour stability of laminate veneers: an in vitro study. J Dent. 2011 Dec;39(1 Suppl 3):e57-64. https://doi.org/10.1016/i.jdent.2011.11.006

3. Burke FJ, Qualtrough AJ, Hale RW. Dentin-bonded all-ceramic crowns: current status. J Am Dent Assoc. 1998 Apr;129(4):45560. https://doi.org/10.14219/jada.archive.1998.0244

4. Guess PC, Schultheis S, Bonfante EA, Coelho PG, Ferencz JL, Silva NR. All-ceramic systems: laboratory and clinical performance. Dent Clin North Am. 2011 Apr;55(2):333-52. https://doi.org/10.1016/i.cden.2011.01.005

5. Addison $O$, Marquis PM, Fleming GJ. Quantifying the strength of a resin-coated dental ceramic. J Dent Res. 2008 Jun;87(6):542-7. https://doi.org/10.1177/154405910808700610

6. Fleming GJ, Maguire FR, Bhamra G, Burke FM, Marquis $P M$. The strengthening mechanism of resin cements on porcelain surfaces. J Dent Res. 2006 Mar;85(3):272-6. https://doi.org/10.1177/154405910608500313

7. Barizon KT, Bergeron C, Vargas MA, Qian F, Cobb DS, Gratton DG et al. Ceramic materials for porcelain veneers: part II. Effect of material, shade, and thickness adjacent tooth substrates is required. In this situation, a more opaque luting agent shade should be used to mask the underlying color, providing appropriate masking ability, and consequentially shade matching with the adjacent teeth. Thus, since scattering and absorption properties might be influenced by the difference in refractive indices between filler and resin matrix, further studies are recommended to evaluate the optical properties of RBLAs loaded with different inorganic filler content, filler shape, and particle size, as well as the long-term effect of aging on color change in luted CLV.

\section{Conclusion}

The variation in inorganic filler content evaluated herein did not significantly influence the TP of simulated CLV; however, all of the tested experimental luting agents presented color change above the perceptibility threshold. Finally, $\mathrm{L}^{*}, \mathrm{a}^{*}$, and $\mathrm{b}^{*}$ individual color coordinates were cementation-dependent. on translucency. J Prosthet Dent. 2014 Oct;112(4):864-70. https://doi.org/10.1016/i.prosdent.2014.05.016

8. Perroni AP, Amaral C, Kaizer MR, Moraes RR, Boscato N. Shade of resin-based luting agents and final color of porcelain veneers. J Esthet Restor Dent. 2016 Sep;28(5):295-303. https://doi.org/10.1111/jerd.12196

9. Alqahtani MQ, Aljurais RM, Alshaafi MM. The effects of different shades of resin luting cement on the color of ceramic veneers. Dent Mater J. 2012;31(3):354-61. https://doi.org/10.4012/dmi.2011-268

10. Almeida JR, Schmitt GU, Kaizer MR, Boscato N, Moraes RR. Resin-based luting agents and color stability of bonded ceramic veneers. J Prosthet Dent. 2015 Aug;114(2):272-7. https://doi.org/10.1016/i.prosdent.2015.01.008

11. Çömlekoğlu ME, Paken G, Tan F, Dündar-Çömlekoğlu M, Özcan M, Akan E et al. Evaluation of different thickness, die color, and resin cement shade for veneers of multilayered CAD/CAM Blocks. J Prosthodont. 2016 Oct;25(7):563-9. https://doi.org/10.1111/jopr.12367

12. Spazzin AO, Guarda GB, Oliveira-Ogliari A, Leal FB, Correr-Sobrinho L, Moraes RR. Strengthening of Porcelain Provided by Resin Cements and Flowable Composites. Oper Dent. 2016 Mar-Apr;41 (2):179-88. https://doi.org/10.2341/15-025-L 
13. Ghavam M, Amani-Tehran M, Saffarpour M. Effect of accelerated aging on the color and opacity of resin cements. Oper Dent. 2010 Nov-Dec;35(6):605-9. https://doi.org/10.2341/09-161-L

14. Archegas LR, Freire A, Vieira S, Caldas DB, Souza EM. Colour stability and opacity of resin cements and flowable composites for ceramic veneer luting after accelerated ageing. J Dent. 2011 Nov;39(11):804-10. https://doi.org/10.1016/i.jdent.2011.08.013

15. Turgut $S$, Bagis B. Effect of resin cement and ceramic thickness on final color of laminate veneers: an in vitro study. J Prosthet Dent. 2013 Mar;109(3):179-86. https://doi.org/10.1016/S0022-3913(13)60039-6

16. Kilinc E, Antonson SA, Hardigan PC, Kesercioglu A. Resin cement color stability and its influence on the final shade of all-ceramics. J Dent. 2011 Jul;39(1 Suppl 1):e30-6. https://doi.org/10.1016/i.jdent.2011.01.005

17. Beun S, Bailly C, Dabin A, Vreven J, Devaux J, Leloup G. Rheological properties of experimental Bis-GMA/ TEGDMA flowable resin composites with various macrofiller/ microfiller ratio. Dent Mater. 2009 Feb;25(2):198-205. https://doi.org/10.1016/i.dental.2008.06.001

18. Jassé FF, Campos EA, Lefever D, Di Bella E, Salomon JP, Krejci I et al. Influence of filler charge on gloss of composite materials before and after in vitro toothbrushing. J Dent. 2013;41 Suppl 5:e41-4. https://doi.org/10.1016/i.jdent.2013.04.011

19. Spazzin AO, Bacchi A, Alessandretti R, Santos MB, Basso GR, Griggs J et al. Ceramic strengthening by tuning the elastic moduli of resin-based luting agents. Dent Mater. 2017 Mar;33(3):35866. https://doi.org/10.1016/i.dental.2017.01.002

20. Nakamura T, Imanishi A, Kashima $H$, Ohyama T, Ishigaki $S$. Stress analysis of metal-free polymer crowns using the three-dimensional finite element method. Int J Prosthodont. 2001 Sep-Oct;14(5):401-5.

21. Salgado VE, Cavalcante LM, Silikas N, Schneider LF. The influence of nanoscale inorganic content over optical and surface properties of model composites. J Dent. 2013 Nov; 41 (5 Suppl 5):e45-53. https://doi.org/10.1016/i.jdent.2013.05.011

22. Lee YK. Influence of scattering/absorption characteristics on the color of resin composites. Dent Mater. 2007 Jan;23(1):124-31. https://doi.org/10.1016/j.dental.2006.01.007

23. Arikawa H, Kanie T, Fujii K, Takahashi H, Ban S. Effect of filler properties in composite resins on light transmittance characteristics and color. Dent Mater J. 2007 Jan;26(1):38-44. https://doi.org/10.4012/dmi.26.38

24. Lee YK. Influence of filler on the difference between the transmitted and reflected colors of experimental resin composites. Dent Mater. 2008 Sep;24(9):1243-7. https://doi.org/10.1016/i.dental.2008.01.014

25. Azzopardi N, Moharamzadeh K, Wood DJ, Martin $N$, van Noort R. Effect of resin matrix composition on the translucency of experimental dental composite resins. Dent Mater. 2009 Dec;25(12):1564-8. https://doi.org/10.1016/i.dental.2009.07.011

26. Lim YK, Lee YK, Lim BS, Rhee SH, Yang HC. Influence of filler distribution on the color parameters of experimental resin composites. Dent Mater. 2008 Jan;24(1):67-73.

https://doi.org/10.1016/j.dental.2007.02.007

27. Boscato N, Hauschild FG, Kaizer MR, De Moraes RR. Effectiveness of combination of dentin and enamel layers on the masking ability of porcelain. Braz Dent J. 2015 Nov-Dec;26(6):654-9. https://doi.org/10.1590/0103-6440201300463

28. Sharma G, Wu W, Dalal EN. The CIEDE2000 color-difference formula: implementation notes, supplementary test data, and mathematical observations. Color Res Appl. 2005;30(1):21-30. https://doi.org/10.1002/col.20070.

29. Johnston WM, Ma T, Kienle BH. Translucency parameter of colorants for maxillofacial prostheses. Int J Prosthodont. 1995 Jan-Feb;8(1):79-86.

30. Vichi A, Ferrari M, Davidson CL. Color and opacity variations in three different resin-based composite products after water aging. Dent Mater. 2004 Jul;20(6):530-4. https://doi.org/10.1016/i.dental.2002.11.001

31. 3M ESPE. RelyX TM Veneer Tecnical Product Profile. 2010.

32. Soares LD, Basso GR, Spazzin AO, Griggs J, Moraes RR. Mechanical reliability of air-abraded and acid-etched bonded feldspar ceramic. Dent Mater. 2016 Mar;32(3):433-41. https://doi.org/10.1016/i.dental.2015.12.011

33. Akın A, Toksavul S, Toman M. Clinical marginal and internal adaptation of maxillary anterior single all-ceramic crowns and 2-year randomized controlled clinical trial. J Prosthodont. 2015 Jul;24(5):345-50. https://doi.org/10.1111/jopr.12217

34. Boening KW, Wolf BH, Schmidt AE, Kästner K, Walter MH. Clinical fit of Procera AllCeram crowns. J Prosthet Dent. 2000 Oct;84(4):419-24. https://doi.org/10.1067/mpr.2000.109125

35. Brawek PK, Wolfart S, Endres L, Kirsten A, Reich S. The clinical accuracy of single crowns exclusively fabricated by digital workflow: the comparison of two systems. Clin Oral Investig. 2013 Dec;17(9):2119-25. https://doi.org/10.1007/s00784-013-0923-5

36. Daronch M, Rueggeberg FA, Goes MF, Giudici R. Polymerization kinetics of pre-heated composite. J Dent Res. 2006 Jan;85(1):38-43. https://doi.org/10.1177/154405910608500106

37. Mundim FM1. Garcia LF, Cruvinel DR, Lima FA, Bachmann L, Pires-de-Souza FC. Color stability, opacity and degree of conversion of pre-heated composites. J Dent. 2011;39 Suppl 1:e25-9. https://doi.org/10.1016/i.jdent.2010.12.001

38. Paravina RD, Ghinea R, Herrera LJ, Bona AD, Igiel C, Linninger $\mathrm{M}$ et al. Color difference thresholds in dentistry. J Esthet Restor Dent. 2015 Mar-Apr;27(1 Suppl 1):S1-9. https://doi.org/10.1111/jerd.12149

39. Nogueira AD, Della Bona A. The effect of a coupling medium on color and translucency of CAD-CAM ceramics. J Dent. 2013 Aug;41(3 Suppl 3):e18-23. https://doi.org/10.1016/i.jdent.2013.02.005

40. Valentini F, Moraes RR, Pereira-Cenci T, Boscato N. Influence of glass particle size of resin cements on bonding to glass ceramic: SEM and bond strength evaluation. Microsc Res Tech. 2014 May;77(5):363-7. https://doi.org/10.1002/jemt.22353 
Erratum: Inorganic filler content of resin-based luting agents and the color of ceramic veneers. Braz Oral Res. 2018;32:e49. http://dx.doi. org/10.1590/1807-3107bor-2018. vol32.0049

The correct Figure 2 is:
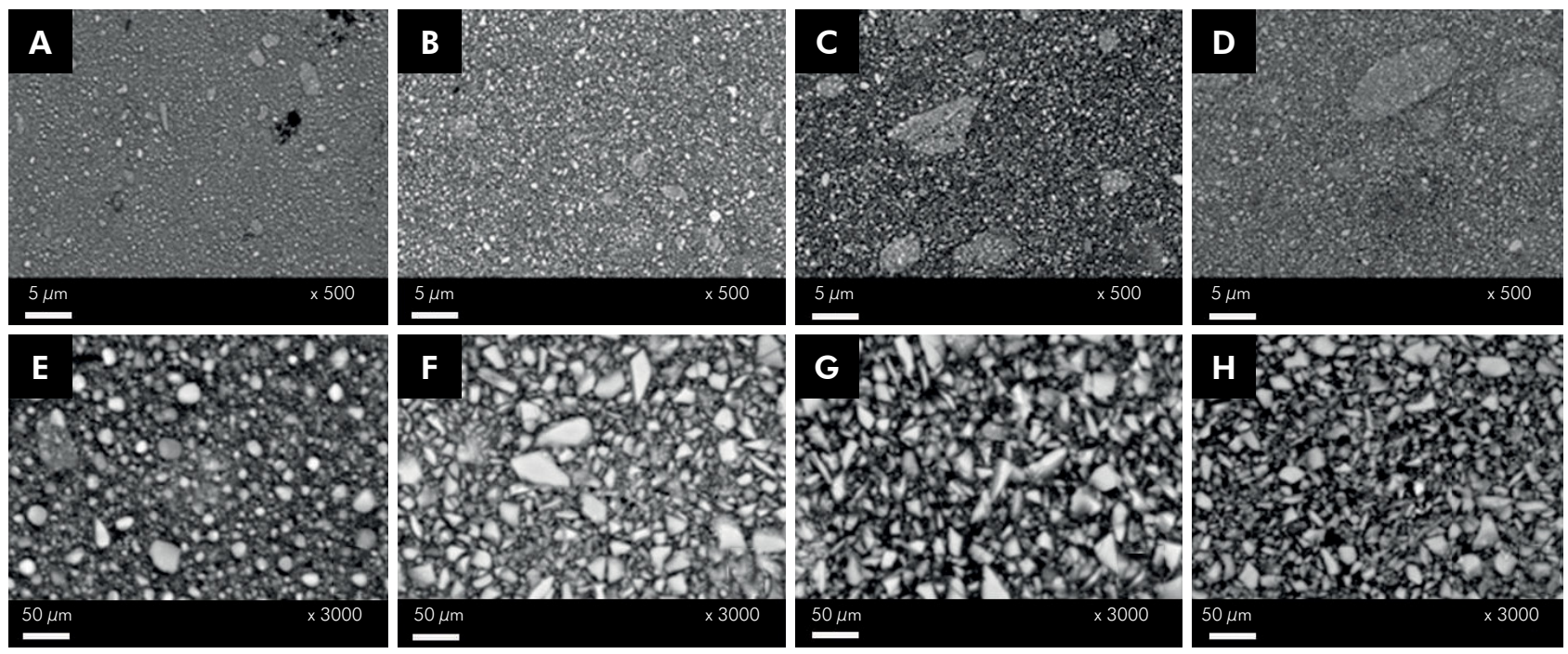